\title{
TEAK VOLUME MODELLING USING MEAN TREE MEASUREMENTS
}

\author{
D P Munaweera \\ Forest Department, Battaramulla.
}

Volume prediction at a kmown precision is essential especially for planmers to make decisions on forest management. Thinning planning, harvesting, limber utilisation for all such activites should be planned based on economical returns, to oblain maximum benefits from these man made forest plantations. Based on the dominant height grow th variations. three Teak rones were jolentilied. In each teak zone several teak trees were felled and true volumes (lotal Volume and the Timber Volume) were calculated and Volume functions were developed for each Teak zome. These volume lunctions were developed using mean tree grow th matsurements of a sland. Therefore it is not to be used fo detemine volumes of individat trees but to calculate the per fiector volune of a stand by measuring the mean parancier values of a stand.

The volume of a felled tree was obtaned by adding volumes of its components. In the log volume calcuation the "Huber"s" equation was used. this equation gives reliable cstimates for any shape of logs other than "neloidic" shape. The Diameter at Breast Height (DBH) and the total height of the tree was recorded before felling the aree. The models tested for heller litting were:

$$
\begin{aligned}
& V=\mathbf{a}+\mathbf{b}^{*} \mathrm{DBH}^{2} * \text { Height }
\end{aligned}
$$

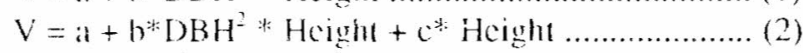

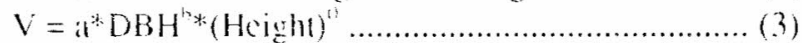

$$
\begin{aligned}
& V=a+b^{*}\left(\mathrm{DBH}^{2}\right) * \text { Height }+\mathrm{C}^{*}(\mathrm{DBH}) \ldots \ldots \ldots \ldots \ldots \text { (4) }
\end{aligned}
$$

In all three zones the hest fits obtained for volume estimation was model 3. This model hats oblatined high correlation in all three zones compared to other models tested.

The volume functions obtained for mean tree volume estimation in three Teak zones are;

$$
\begin{aligned}
& \text { Zone } 1: \mathrm{V}=.000013 *(\mathrm{DBH})^{2.5111} *(\text { Height } \\
& \text { Zone } 2: \mathrm{V}=.000102 *(\mathrm{DBH})^{1.9063} *(\text { Height }) \\
& \text { Zone } \left.3: \mathrm{V}=.000102 *(\mathrm{DBH})^{1.8885} * \text { (Height }\right)^{.815}
\end{aligned}
$$

\footnotetext{
Proceedings of the Fourth Annual Forestry and Environment Symposium 1998 of the Department of Forestry and Environmental Science. University of Sri Jayewardenepura, Sri Lanka
} 